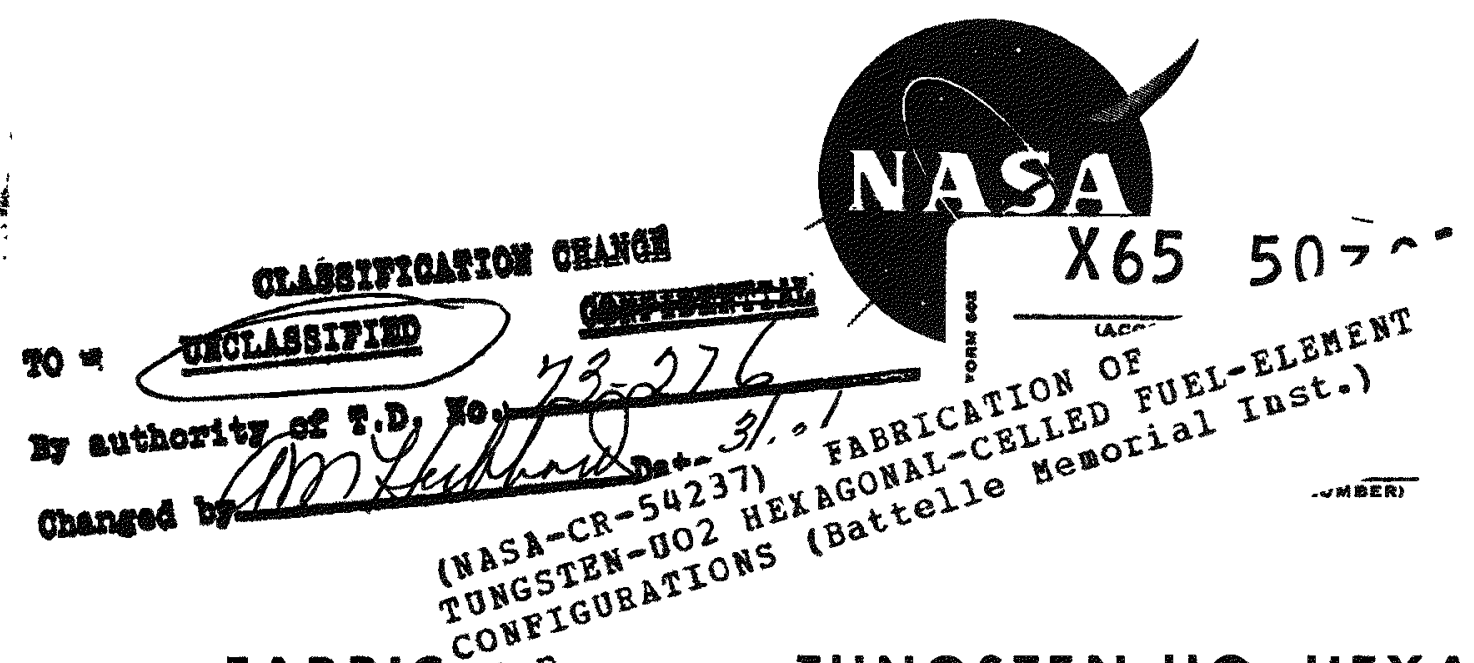

NASA CR -54237

FABRIC ${ }_{25}{ }^{\circ}$ IT TUNGSTEN-UO 2 HEXAGONALCELLED FUEL-ELEMENT CONFIGURATIONS by

Y. R. Goetsch, P. W. Cover, P. J. Gripshover, and W. J. Wilson prepared for

NATIONAL AERONAUTICS AND SPACE ADMINISTRATION

CONTRACT NAS $3-5216$
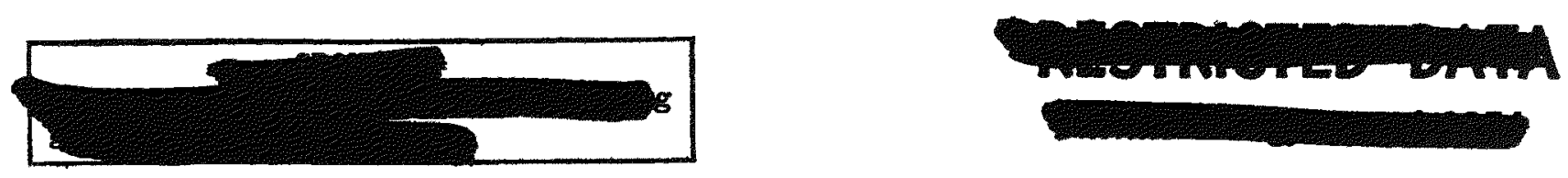

\title{
BA $\mathrm{A}$ T I I I
}

M IIMOIIAI I IBTITUTE 


\section{DISCLAIMER}

This report was prepared as an account of work sponsored by an agency of the United States Government. Neither the United States Government nor any agency Thereof, nor any of their employees, makes any warranty, express or implied, or assumes any legal liability or responsibility for the accuracy, completeness, or usefulness of any information, apparatus, product, or process disclosed, or represents that its use would not infringe privately owned rights. Reference herein to any specific commercial product, process, or service by trade name, trademark, manufacturer, or otherwise does not necessarily constitute or imply its endorsement, recommendation, or favoring by the United States Government or any agency thereof. The views and opinions of authors expressed herein do not necessarily state or reflect those of the United States Government or any agency thereof. 


\section{DISCLAIMER}

Portions of this document may be illegible in electronic image products. Images are produced from the best available original document. 


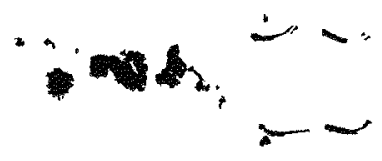

\section{NOTICE}

This report was prepared as an account of Government sponsored work. Neither the United States, nor the National Aeronautics and Space Administration (NASA), nor any person acting on behalf of NASA:

A.) Makes any warranty or representation, expressed or implied, with respect to the accuracy, completeness, or usefulness of the information contained in this report, or that the use of any information, apparatus, method, or process disclosed in this report may not infringe privately owned rights; or

B.) Assumes any liabilities with respect to the use of, or for damages resulting from the use of any information, apparatus, method or process disclosed in this report.

As used above, "person acting on behalf of NASA" includes any employee or controctor of NASA, or employee of such contractor, to the extent that such employee or contractor of NASA, or employee of such contractor prepares, disseminates, or provides access to, any information pursuant to his employment or contract with NASA, or his employment with such contractor.

Requests for copies of this report should be referred to:

National Aeronautics and Space Administration Office of Scientific and Technical Information Washington 25, D.C.

Attention: AFSS-A 


\section{FIRST QUARTERLY PROGRESS REPORT}

(June 30 to September 30,1964 )

FABRICATION OF TUNGSTEN-UO 2 HEXAGONAL-

CELLED FUEL-ELEMENT CONFIGURATIONS (Q) (U)

by

G. R. Goetsch, P. W. Cover, P. J. Gripshover, and W. J. Wilson

prepared for

NATIONAL AERONAUTICS AND SPACE ADMINISTRATION
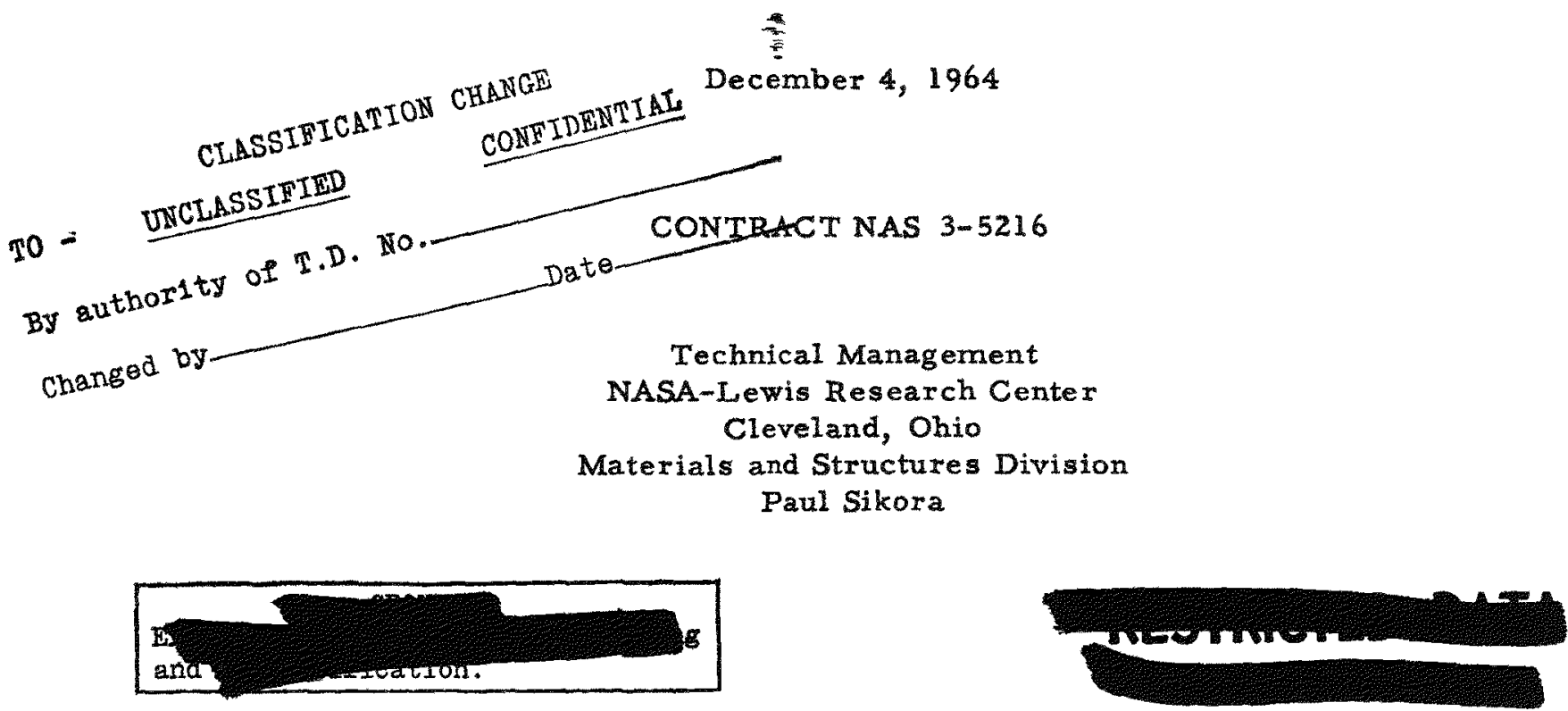

BATTELLE MEMORIAL INSTITUTE 505 King Avenue Columbus, Ohio 43201 
TABLE OF CONTENTS

Page ABSTRACT . . . . . . . . . . . . . . . . . . . . . . . . 1

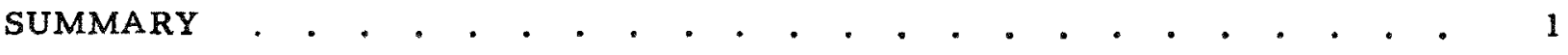
INTRODUCTION • . • . . . . . . . . . . . . . . . . . 2 WORK CONDUCTED TO DATE

Phase I. Optimization of Fuel Materials . . . . . . . . . . . 3 Effects Produced by Various Containers and Pretreatments . . . 3 Coated-Particle Evaluation. . . . . . . . . . . . . . 10 Additional Studies of Materials.

Phase II. Honeycomb Fabrication Goals of Phase II

Fabrication of Exploratory Specimens End-Fixture Evaluation

FUTURE WORK

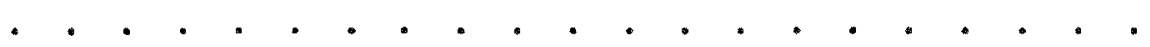

21 


\section{ABSTRACT}

$$
50301
$$

The gas-pressure-bonding process is being evaluated as a means of fabricating tungsten- $\mathrm{UO}_{2}$ hexagonal-celled fuel geometries. A two-part study was initiated to optimize the fuel materials and to develop the required fixturing and loading techniques. Production of fueled tungsten-coated $\mathrm{UO}_{2}$ particles is in progress so that geometries embodying coated particles or coated particles plus fine tungsten powder can be evaluated. Tests to date have shown the requirement for a pretreatment in which a gaseous oxide phase is removed. Initial loading and fixturing procedures were proven satisfactory by the fabrication of a 19-cylindrical-hole hexagonal-type composite.

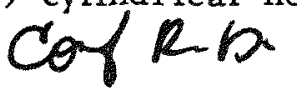

\section{SUMMARY}

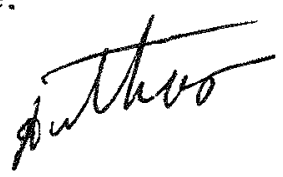

The work reported concerns the fabrication of dense, tungsten-20 volume percent $\mathrm{UO}_{2}$ composite, honeycomb-type, fuel-element configurations by employing the gaspressure-bonding process. The effort is divided into two areas - Phase I, determination of the necessary procedures for obtaining densities in excess of 98 percent of theoretical and Phase II, experimentation of various loading and fixturing techniques to provide the specified configuration and dimensional tolerances.

With regard to Phase 1 , tests were conducted in which container effects, tantalum gettering characteristics, and tungsten-powder pretreatments were related to porosity in the composites. To date, the presence of an oxide gaseous phase within a sealed container containing tungsten powder has been confirmed. This gas is believed to be responsible for the lack of sufficient densification. Hot vacuum degassing techniques are currently being examined as an effective method for removing the gas.

Concurrent with the above study is the evaluation of tunsten-coated $\mathrm{UO}_{2}$ particles with emphasis on producing high-purity particles. Conclusive results are not yet available. Other tests regarding the material system have included the successful hot isostatic compaction of a sample of 2 weight percent thoria-tungsten powder. A resultant density of 97.5 percent of theoretical suggests that this material should be used in the future honeycomb composites as the matrix material.

Phase II efforts have produced a 19-hole exploratory tungsten specimen consisting of cylindrical holes, $1 / 8$ inch in diameter, inside a 3/4-inch tube, 2 inches long. This specimen displayed dimensional tolerances on the web thickness and on the straightness

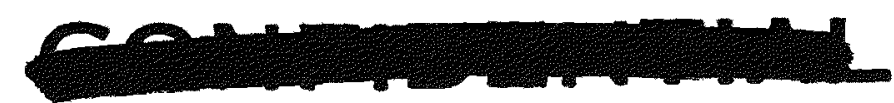




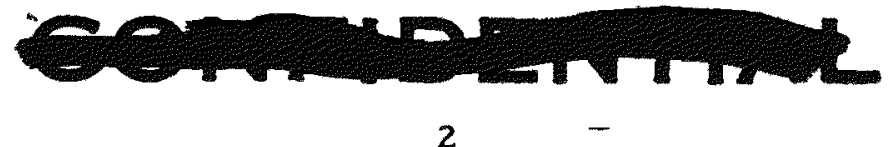

2

of the holes within 1 mil. The specimen was fabricated by pressure bonding tungsten granules at parameters of $2900 \mathrm{~F}$ and $10,000 \mathrm{psi}$ for 3 hours. The dimensional survey data were used to design the fixtures for a 61-hole hexagonal-celled structure of the same material. The success of the first specimen has demonstrated that this fabrication process is practical.

\section{INTRODUCTION}

One current nuclear-reactor design for nuclear propulsion in space is the watermoderated type, embodying dispersions of $\mathrm{UO}_{2}$ particles in a continuous tungsten matrix as the fuel system. This material combination is very attractive with regard to high-temperature properties; however, one major problem area concerns the high degree of difficulty encountered in fabricating desirable fuel-element geometries. Although some processes have been successfully used to fabricate dense tungsten- $\mathrm{UO}_{2}$ composites, these composites are not easily fabricable into the geometries proposed for the nuclear rocket, such as concentric cylinders and hexagonal-celled honeycombs. For this reas on, new powder-metallurgy approaches to producing these fuel geometries have been receiving considerable attention. The most encouraging processes established at present for the honeycomb configuration are those involving sintering, highenergy compaction, and hot isostatic compaction. The last process is the one considered in this program (under NASA Contract NAS 3-5216).

The purpose of this investigation is to utilize the gas-pressure-bonding process to isostatically compact dense, honeycomb-type, 80 volume percent tungsten-20 volume percent $\mathrm{UO}_{2}$, fuel-element configurations. This fabrication technique is of particular interest since it has demonstrated its capabilities and versatility with various fuel systems by producing unique fuel geometries with a relatively small amount of fuel-particle deformation. As a means of providing uniformity of fuel distribution and good fuelretention properties, tungsten-coated $\mathrm{UO}_{2}$ particles will be employed in the composites. The combination of these particles with the gas-pressure-bonding process should provide a means whereby the desired fuel-element configuration can be produced.

Since this program is a fabrication-feasibility study, the problem of producing the fueled composites is divided into two areas of effort - the first, investigation of materials and pressure-bonding parameters to attain composite densities in excess of 98 percent of theoretical; the second, development of a method to hot isostatically compact a honeycomb structure with the desired dimensional tolerances throughout the structure. These two studies are designated Phase I and Phase II, respectively. Phase I involves the experimentation with various container materials, preliminary heat treatments, and coated particles in order to assure high-quality dense composites. In Phase II, the loading and fixturing techniques required for dimensional uniformity will be investigated. Success in both of these areas is necessary to establish the feasibility of using the gas-pressure-bonding process for the fuel-element fabrication.

This report summarizes the results of studies conducted during the first 3-months of this program (June 30 to September 30, 1964). 


\section{WORK CONDUCTED TO DATE}

Prior to the discussion of the work conducted to date, a review of the gaspressure-bonding process and its associated procedures is in order.

In consolidating powder materials, the powder is sealed within a pressure-tight container of the desired geometry. This container is then loaded into an autoclave and subjected to elevated temperatures and high-pressure inert gas. The pressure is uniformly transmitted through the container walls isostatically to the contained powders, which are effectively hot pressed to the desired density and configuration. The degree of densification is dependent upon the bonding parameters of time, temperature, and pressure. In general, the bonding temperatures for powder consolidation are considerably below those for conventional sintering and also those for a number of other fabrication methods. The use of thin-wall containers and mandrels, where appropriate, permits the fabrication of various hollow and solid shapes from powder. The containers and mandrels are generally removed by mechanical or chemical means.

\section{Phase I. Optimization of Fuel Materials}

\section{Effects Produced by Various Containers and Pretreatments}

Previous work at Battelle under NASA contracts has shown that the gas-pressurebonding process can be used to fabricate various shapes; however, the process has not produced tungsten- $\mathrm{UO}_{2}$ structures of the desired density. During this work, it was discovered that tungsten $-\mathrm{UO}_{2}$ composites consolidated within tantalum containers were more dense than those produced within molybdenum containers. (The latter material had been used exclusively because of its compatibility with tungsten and $\mathrm{UO}_{2}$ at the bonding temperatures and its chemical properties, which allowed selective leaching of the container.) The greater densities attained in tantalum containers suggested that a gaseous phase was present within the molybdenum containers, which caused restriction of further densification. The presence of the gas could be produced by the molybdenum container or the powder composite. Tantalum, being an effective getter, would allow the composite to densify more than one in molybdenum. The problem of obtaining highdensity composites then becomes one of either removing the suspected gas prior to sealing or the incorporation of an effective getter into the pressure-bonding container.

Some of the $1 \times 6 \times 0.020$-inch flat plates fabricated under a previous NASA contract (NAS 3-4019) were consolidated using a molybdenum container with a sheet of 1-mil tantalum foil situated between the powder composite and the container on one of the large flat surfaces. Metallographic examination of these plates suggested a layer of tantalum diffusion within the composite. To determine the extent, if any, of the diffusion, a microprobe analysis was conducted across the whole thickness of the plate.

Results of this analysis were very enlightening. A 6-micron-thick layer, which consisted of 79 weight percent tantalum, was found on the tantalum contact edge. Beyond this layer, the tantalum content decreased linearly across the whole thickness from 17 to 1 weight percent. This finding not only confirms the diffusion process but

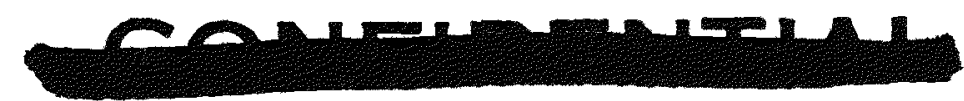




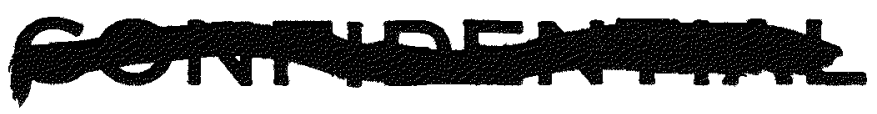

4

also suggests that some other mechanism, such as vapor transport, is in action. Although the mechanism is not established, the conclusion is rather clear: tantalum's gettering qualities cannot be utilized in a powder system unless contact between it and the active tungsten powder is avoided. With this fact in mind, the following objectives were set up for additional tests: prove the existence of the proposed gaseous phase; identify its nature; determine an effective way for its removal prior to densification; and determine which container material will be the best for fabricating future specimens. To achieve these objectives, the following tests were conducted.

Test 1. From a lot of 0.88-micron tungsten powder (see Table 1 for vendor's analysis) which had been previously cleaned in hydrogen at $2000 \mathrm{~F}$ for 1 hour, unfueled tungsten pellets (approximately $1 / 4$ inch in diameter and 3/4 inch long) were formed to a density of approximately 58 percent of theoretical by hydropressing at 100,000 psi. (Pellets produced by this procedure shall subsequently be referred to as "standard" pellets.) Two of these pellets were separately loaded within molybdenum containers, and two were encased within tantalum containers. One container of each material was sealed by the electron-beam-welding process. These four specimens were then vacuum sintered at $3632 \mathrm{~F}$ for 1 hour. Evaluation consisted of metallographic examination of the pellets and containers. As shown in Figures 1 and 2, a large improvement in density was achieved in the pellet sintered in the open molybdenum container. In addition, the grain size and pore size of this pellet are much smaller than they are in the pellet sintered in the closed molybdenum container. A similar improvement, only to a lesser degree, was found in the pellets sintered in tantalum containers, Figures 3 and 4 .

Since the pellets in the open containers have been exposed to a dynamic vacuum during sintering, the effects of any evolved gases are not felt. The closed containers, on the other hand, have been exposed to the gas, as suggested by the microstructure and the fact that the sealed containers were slightly bulged. A second point of interest is that the density of the pellet sintered in the sealed tantalum is superior to that of the pellet sintered in the sealed molybdenum. This is evidently due to tantalum's gettering qualities, in that it actually absorbs most of the gas. Numerical values for the pellet densities were not obtained because only a qualitative comparison is required to establish conclusions. This policy will be used until the densification studies are carried to pressure-bonded samples.

TABLE 1. VENDORS' CHEMICAL ANAL YSIS OF STARTING MATERIALS

\begin{tabular}{|c|c|c|c|c|c|c|c|c|c|c|c|}
\hline $\begin{array}{l}\text { Starting } \\
\text { Material }\end{array}$ & $\mathbf{N}$ & 0 & C & $\mathrm{Al}$ & $\mathrm{Ca}$ & $\mathrm{Cr}$ & $\mathrm{Fe}$ & $\mathrm{Mg}$ & Mo & $\mathrm{Ni}$ & $\mathrm{Si}$ \\
\hline $\begin{array}{l}\text { Tungsten } \\
(0.88 \mu)\end{array}$ & -- & 1700 & 11 & $<6$ & 13 & 6 & 25 & 6 & 26 & 10 & $<7$ \\
\hline $\begin{array}{l}\mathrm{UO}_{2} \\
\quad(-230+325 \text { mesh })\end{array}$ & 100 & $\begin{array}{l}(0 / \mathrm{U}) \\
2.00 \text { to } \\
2.02\end{array}$ & 100 & 50 & 10 & 50 & 100 & $=-$ & 30 & -- & 30 \\
\hline
\end{tabular}

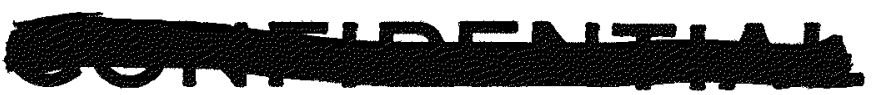



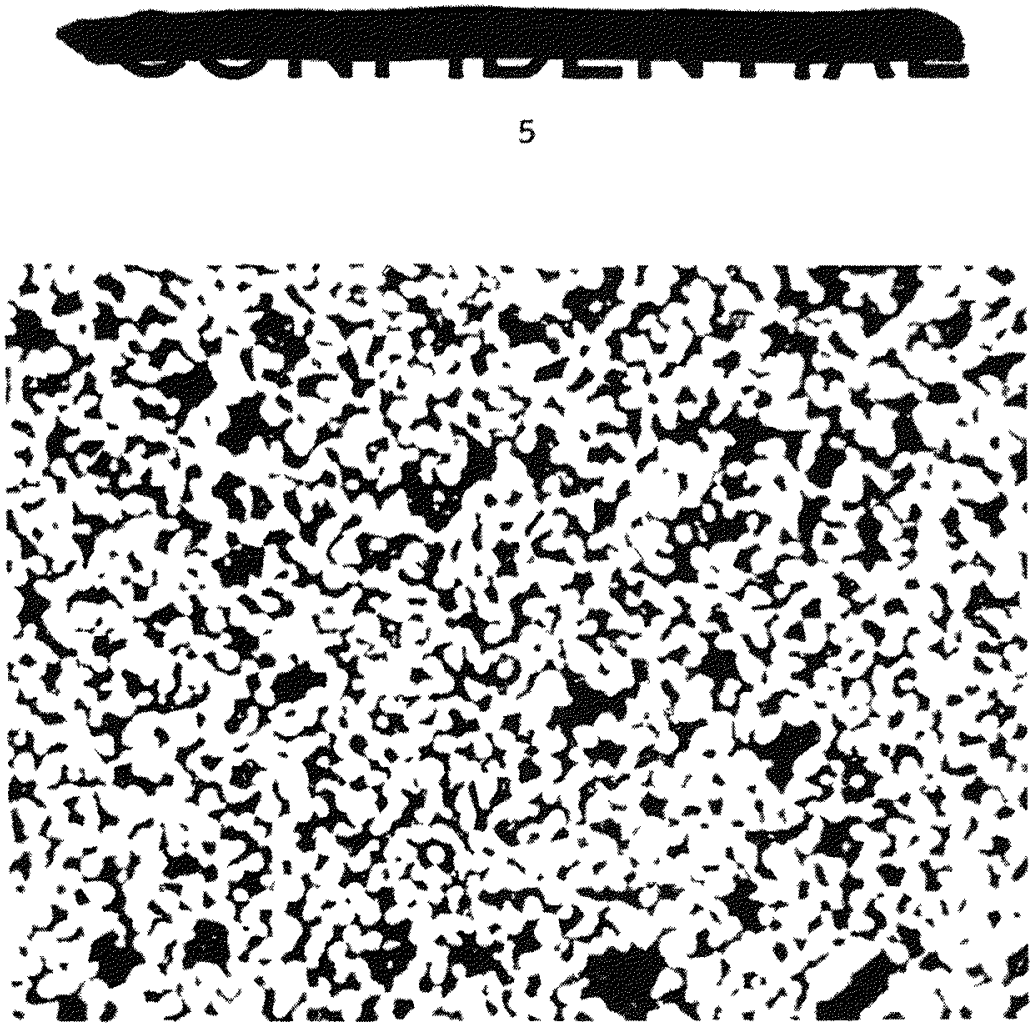

$250 \mathrm{x}$

As Polished

13894

FIGURE 1 * HYDROPR ESSED TUNGSTEN POWDER SINTERED IN A SEALED MOLYBDENUM CONTAINER

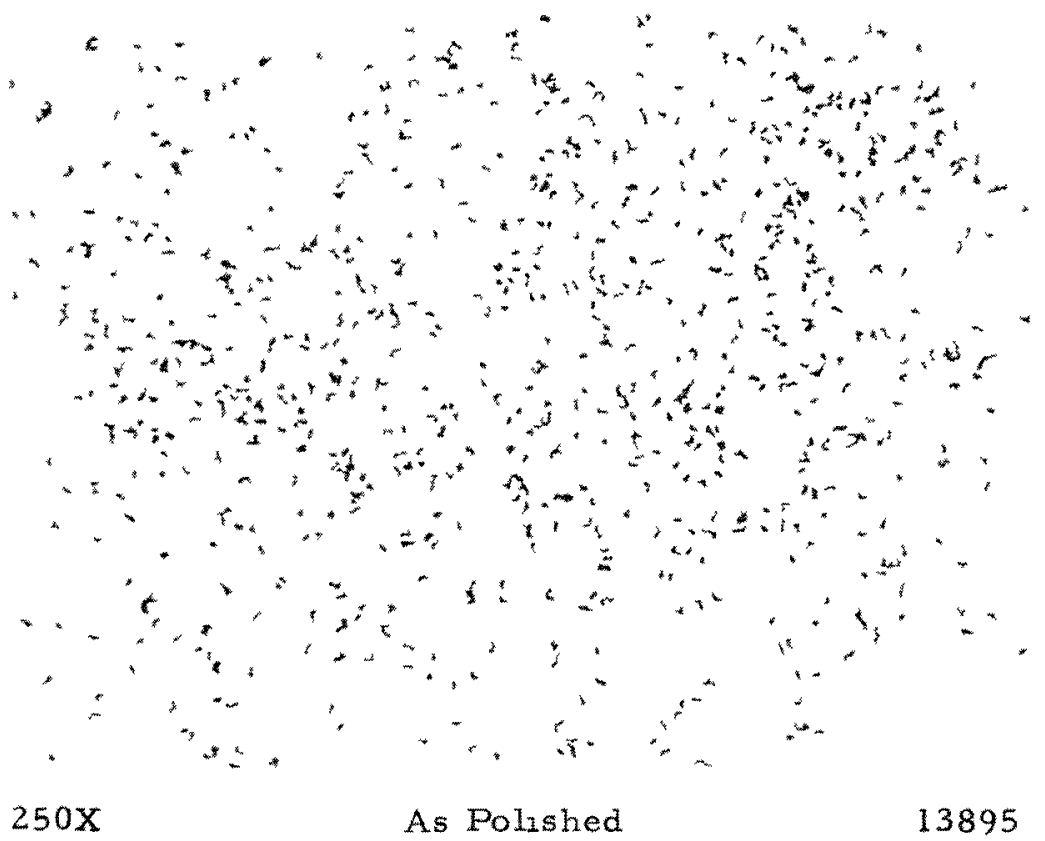

FIGURE 2 HYDROPRESSED TUNGSTEN POWDER SINTERED IN AN OPEN MOLYBDENUM CONTAINER

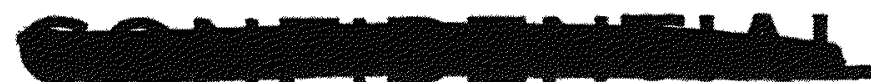




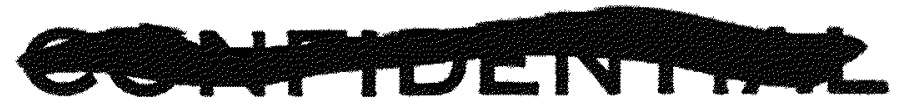

6

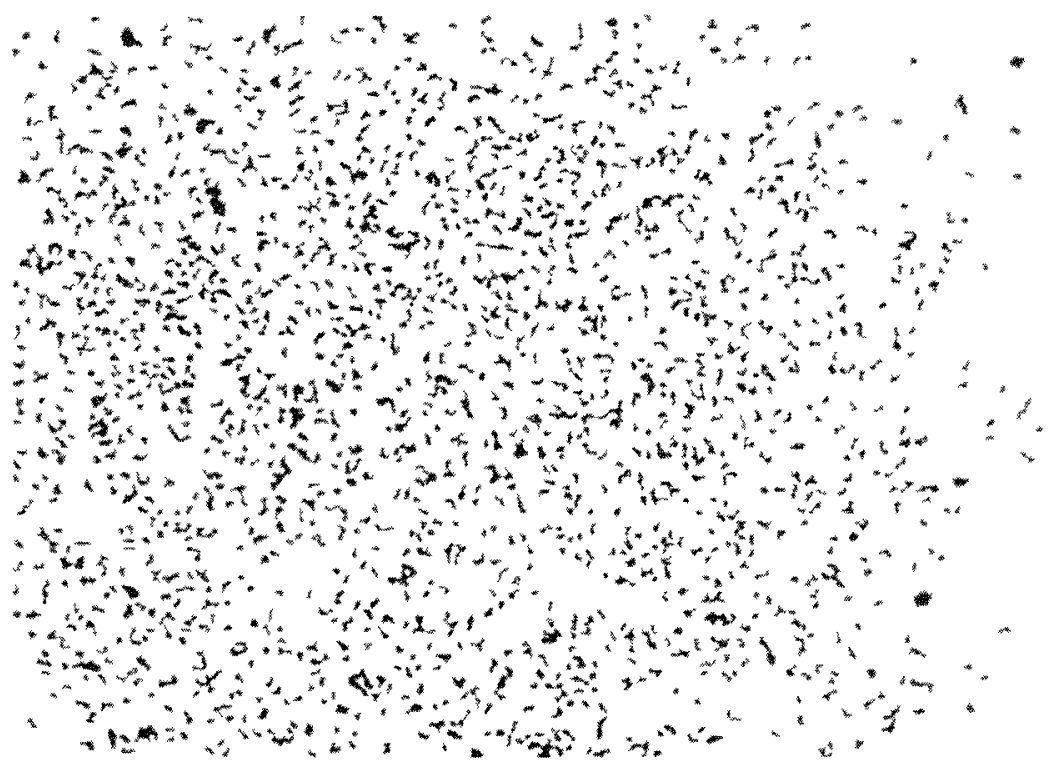

$250 \mathrm{X}$

As Polished

13896

FIGURE 3 - HYDROPRESSED TUNGSTEN POWDER SINTERED IN A SEALED TANTALUM CONTAINER

FIGURE 4 HYDROPRESSED TUNGSTEN POWDER SINTFRED IN AN OHEN TANTALUM CONTAINER 
Further evidence that a gaseous contaminant does exist was found during evaluation of the containers. Figures 5 and 6 show typical areas on the inside surfaces of the sealed containers with contaminated layers. These layers were tentatively identified by microscopic observations as oxide layers. As additional proof, oxygen analyses of the materials prior to and after sintering (see Table 2) showed that a substantial amount of oxygen was gettered by the tantalum during sintering. Therefore, this test has shown that a gaseous phase does exist, and that it is probably an oxide.

\section{TABLE 2. OXYGEN ANALYSIS BEFORE AND AFTER} SINTERING

\begin{tabular}{lc}
\hline \multicolumn{1}{c}{ Specimen } & $\begin{array}{c}\text { Oxygen Content, } \\
\text { ppm }\end{array}$ \\
\hline As-received molybdenum & 41 \\
Sealed molybdenum container - Test 1 & 202 \\
As-received tantalum & 322 \\
Sealed tantalum container - Test 1 & 1520 \\
Sealed tantalum containex - Test 2 & 1245 \\
\hline \hline
\end{tabular}

Test 2. Three standard pellets were individually loaded within molybdenum, tantalum, and molybdenum-lined tantalum containers. The last container was produced by lining the inside cavity of the tantalum can with 3-mil-thick molybdenum foil. Prior to sealing the cans, the specimens were kept red hot for 10 minutes by using the electron beam. After sealing, the specimens were then sintered at $3632 \mathrm{~F}$ for 1 hour as in the previous test. Two observations were obvious from metallographic examination of the specimens. Figure 7 and Figure 8 represent the structures produced in the sealed molybdenum and molybdenum-lined tantalum containers, respectively. First, the densities of the pellets in the sealed molybdenum and tantalum containers were slightly higher than those observed in the previous test (see Figures 1 and 3). Second, the density of the pellet sintered in the molybdenum-lined tantalum container was slightly lower than that produced in the bare tantalum can. This suggests that the liner restricted the densification by either being the cause of the oxide phase or by decreasing the effectiveness of tantalum's gettering characteristics. An oxygen analysis of the tantalum container, Table 2, showed a marked decrease in oxygen content, indicating that the hot vacuum outgassing treatment reduced the quantity of gas evolved during the subsequent sintering treatment. Thus, this test has shown that the oxide phase can be reduced by hot vacuum degassing and that a molybdenum liner has only a slight restricting action.

Test 3. Three specimens were pressure bonded at $2900 \mathrm{~F}$ and 10,000 psi for 3 hours. One specimen consisted of pieces of the four sintered pellets from Test 1 encased within a molybdenum container in hopes that the cleaned compacts would achieve high density.

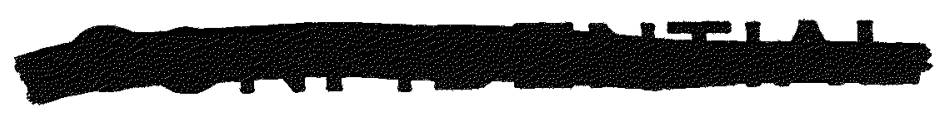




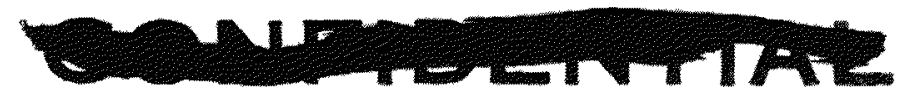

8

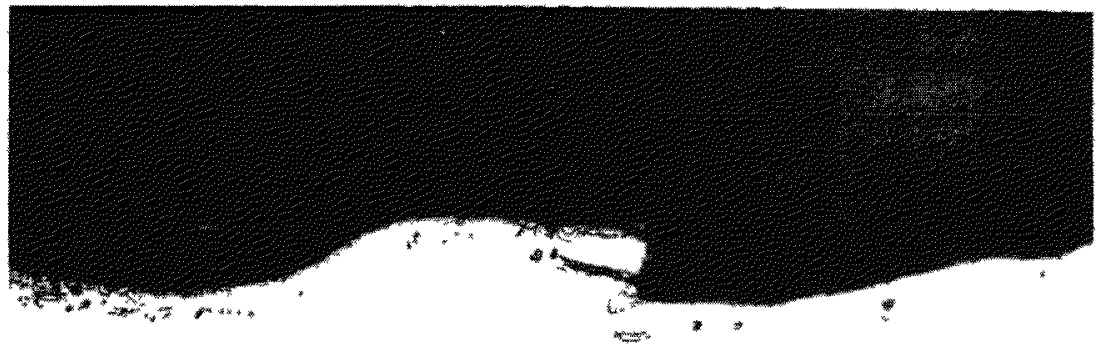

$250 \times$

As Polished

13943

FIGURE 5. CONTAMINATION ON THE INTERNAL SURFACE OF A SEALED MOLYBDENUM CONTAINER AFTER SINTERING

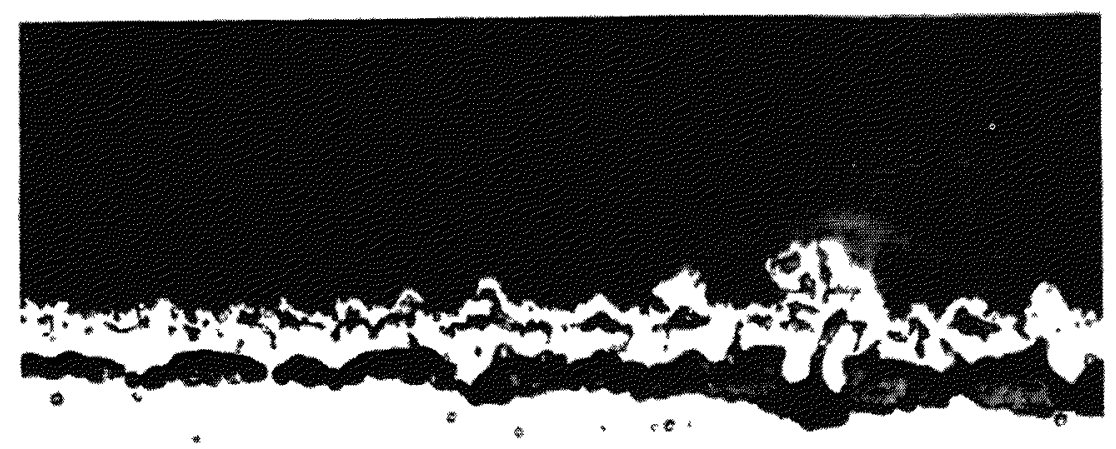

FIGURE 6. CONTAMINATION ON THE INTERNAL SURFACE OF A SEALED TANTALUM CONTAINER AFTER SINTERING 
9

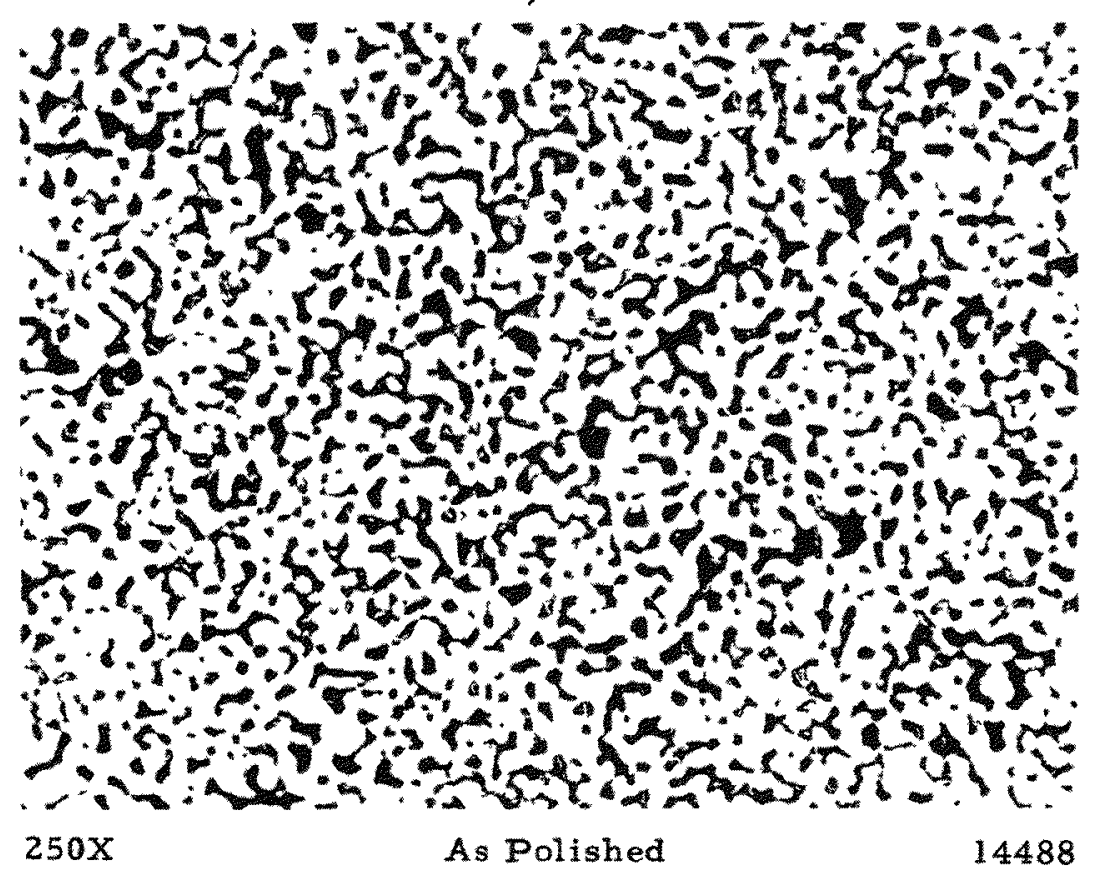

FIGURE 7. HYDROPRESSED TUNGSTEN POWDER HOT OUTGASSED IN ELECTRON BEAM THEN SEALED AND SINTERED IN A MOLYBDENUM CONTAINER

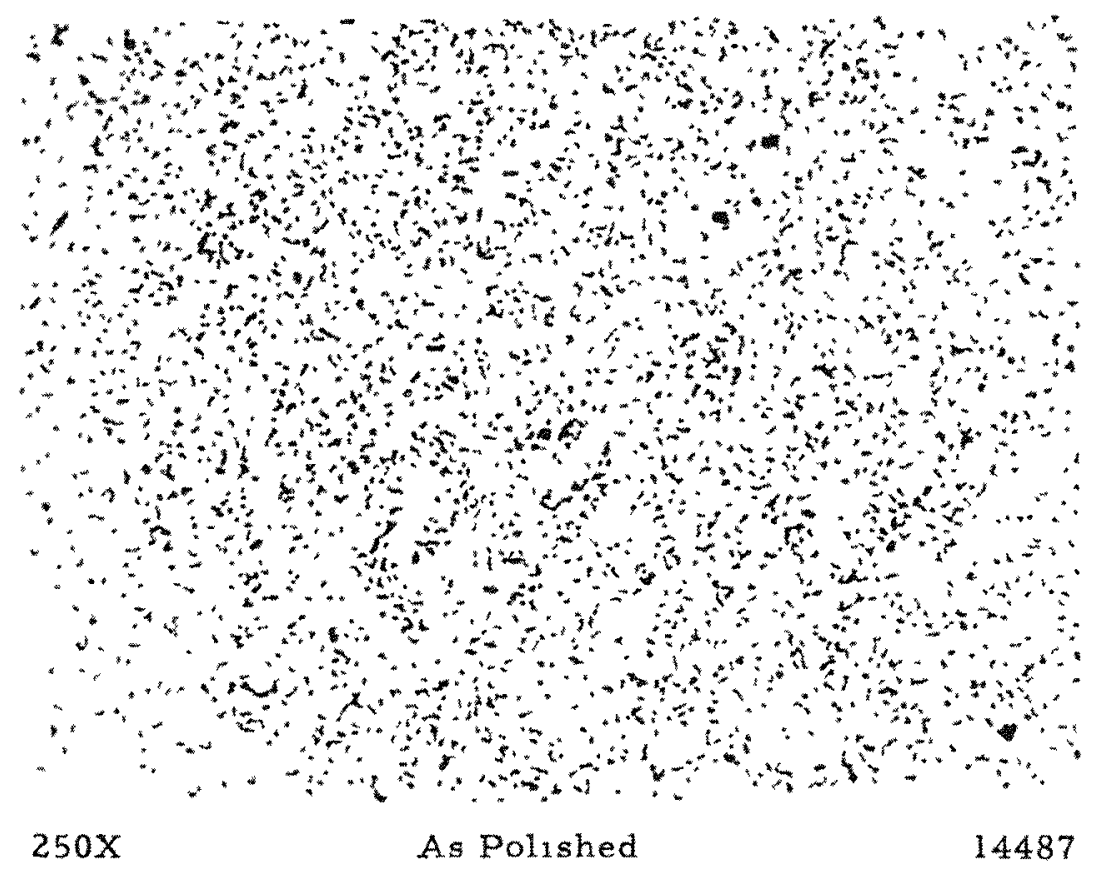

FIGURE 8, HYDROPRESSED TUNGSTEN POWDER HOT OUTGASSED IN ELECTRON BEAM THEN SEALED AND SINTERED IN A TANTALUM CONTAINER 


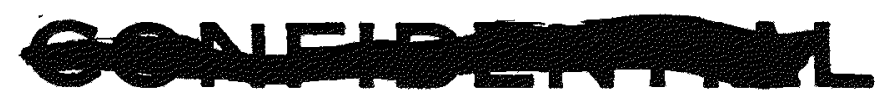

10

The densities of the four sintered pellets were slightly higher than those produced by sintering alone. The appearance of the microstructures suggests that densification was due to plastic flow of the powder only and not to a sintering mechanism. Therefore, to provide a fully dense structure after pressure bonding, pretreatment temperatures will have to be kept under $3600 \mathrm{~F}$ so as not to reduce the surface activity of the tungsten powder, or considerably higher bonding parameters must be employed.

The other two specimens consisted of molybdenum-lined tantalum and molybdenumlined titanium containers embodying standard pellets. Metallography on these two specimens showed estimated densities of about 95 and 92 percent, respectively. Titanium does not appear to be as effective a getter as tantalum in this application.

\section{Coated-Particle Evaluation}

Tungsten- $\mathrm{UO}_{2}$ composites fabricated by consolidation of tungsten-coated $\mathrm{UO}_{2}$ particles (containing 20 volume percent $\mathrm{UO}_{2}$ ) during previous programs possessed two disadvantages - the presence of excess fluorine, due to the coating process, and inherent interconnected porosity, which resulted when densities of only 92 percent of theoretical were achieved. Therefore, the purpose of this study is to conduct a limited evaluation of different types of coating processes in an effort to eliminate excess contamination (particularly halides) and to attempt complete densification of these particles by employing new maximum pressure-bonding parameters of $3100 \mathrm{~F}$ and 30,000 psi.

To date, all the desired coated particles (containing 20 volume percent $\mathrm{UO}_{2}$ ) have been produced, but complete analyses and evaluations are not yet available. The $\mathrm{UO}_{2}$ used for all the coatings was spherical, depleted material of $-230+325$ mesh size. Chemical analys is of this material is given in Table 1. The five types of coatings are discussed below.

Coating A. This coating, Figure 9, was prepared by decomposing $\mathrm{WCl}_{6}$ in a hydrogen atmosphere at $1290 \mathrm{~F}$ to provide material for comparison with the fluoridederived Coating B, Figure 10. The two chief points of comparison will be (1) pressurebonding characteristics and (2) the extent of halide contamination. Evaluation of the sample is incomplete; however, metallographic examination shows a discoloration of the inner portion of the coating. This abnormality undoubtedly resulted from unsuspected contamination of the $\mathrm{WCl}_{6}$, but its significance is not yet known.

Coating B. This dense coating (see Figure 10) was prepared at $1030 \mathrm{~F}$ by de composing $\mathrm{WF}_{6}$ in a fluidized bed. This is the most convenient and economical means of applying tungsten coatings to particles; however, a small, but for this program significant, fluorine content (436 ppm) is observed in the coated particles. This material was prepared to determine its pressure-bonding characteristics and to establish a base for determining the effectiveness of procedures designed to reduce fluorine contamination.

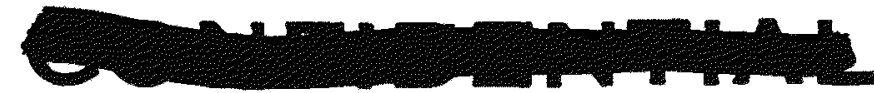



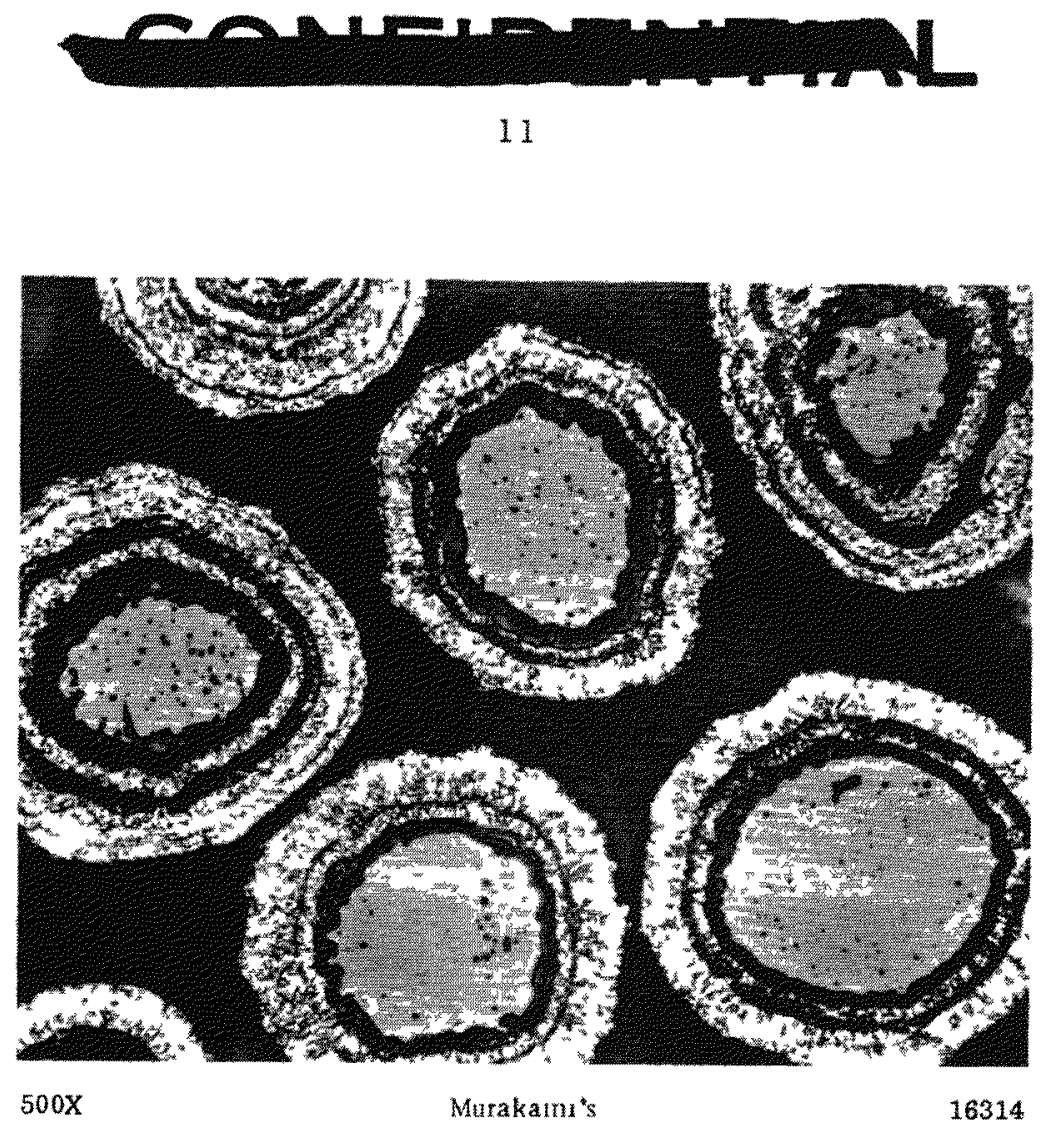

FIGURE 9 . TUNGSTEN-COATED UO 2 PARTICLES PRODUCED BY THE REDUCTION OF TUNGSTEN HEXACHLORIDE (COATING A)

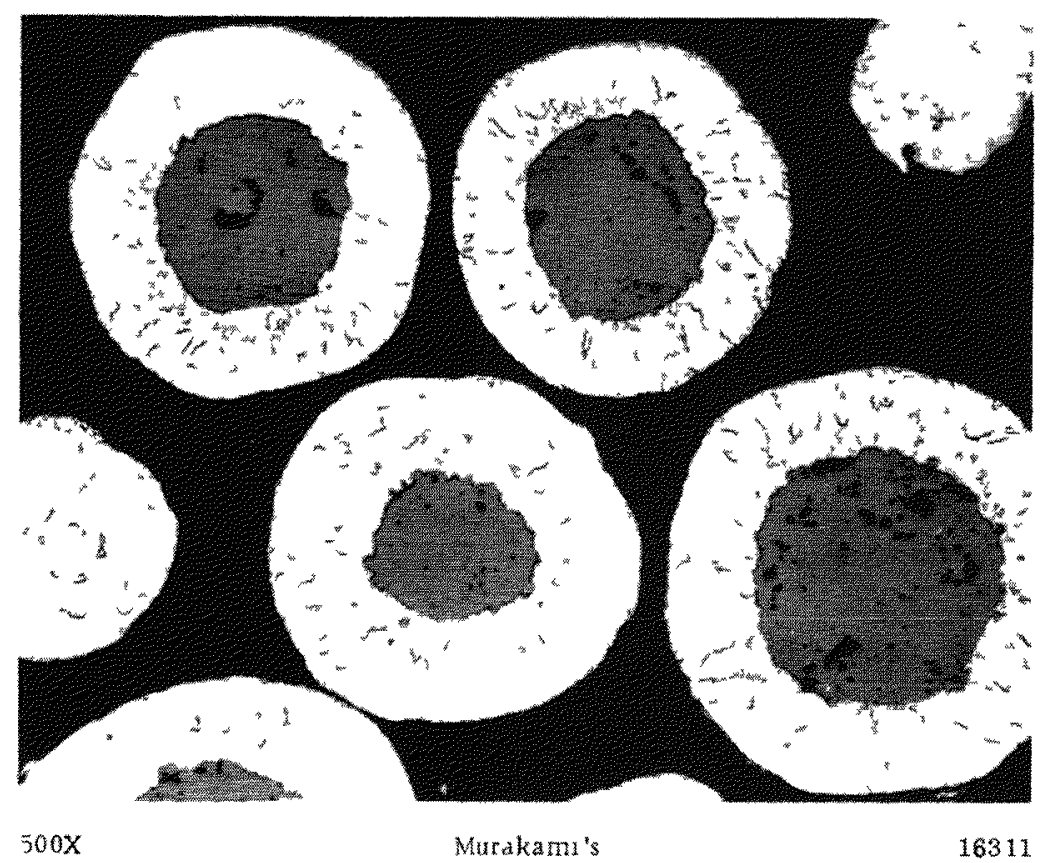

FIGURE 10 TUNGSTEN-COATED UO 2 PARTICLES PRODUCED BY THE REDUCTION OF TUNGSTEN HEXAF LUORTDE (COATING B) 


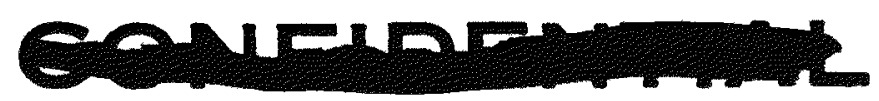

12

Coating C. As was the case for Coating B, this coating was prepared by decomposing WF 6 at $1030 \mathrm{~F}$. However, the procedure was altered in an attempt to decrease the fluorine content of the final material. After about $1 \mu$ of tungsten had been applied to the substrate, the material was removed from the fluidized-bed reactor and treated at $2550 \mathrm{~F}$ for 2 hours in a flowing atmosphere of hydrogen containing 3 percent water vapor. The material was then returned to the fluidized-bed reactor and the coating completed in the usual manner. Figure 11 shows the similarity this coating has with Coating $\mathbf{B}$.

It is probable that at least a portion of the fluorine contamination of tungstencoated materials, prepared by decomposition of the hexafluoride, results from reactions of fluoride in the coating atmosphere with the $\mathrm{UO}_{2}$ substrate during early stages of the operation before the tungsten coating is sufficiently thick to protect the UO . For example, the reaction

$$
\mathrm{UO}_{2}(\mathrm{~s})+2 \mathrm{WF}_{6}(\mathrm{~g}) \rightarrow 2 \mathrm{WOF}_{4}(\mathrm{~g})+\mathrm{UF}_{4}(\mathrm{~s}) \Delta \mathrm{F}_{900 \mathrm{~K}}-25 \mathrm{kcal}
$$

is energetically favorable. Therefore, the wet-hydrogen treatment was designed to remove fluoride as HF, formed by the hydrolysis of uranium fluoride or oxyfluoride at the surface of the $\mathrm{UO}_{2}$ particles.

The thickness of the tungsten coating at the time of such treatment should be the optimum that would permit removal of fluoride yet minimize fluoride pickup in the next coating step.

For this particular lot, the thickness of tungsten coating and conditions of the treatment given above represent experienced judgment, but it is highly improbable that they are optimum values. Nevertheless, the final material prepared with this intermediate treatment contained only $237-\mathrm{ppm}$ fluorine, i.e., a 50 percent decrease in fluorine content was achieved.

There is little doubt that further reduction in fluorine content could be achieved by brief experimental work designed to optimize the procedure.

Coating D. To minimize contamination with fluorine during preparation of this material, another variation of the normal procedure for tungsten coating from WF 6 , represented by Coating $B$, was used. This coating is identical in appearance to Coatings $B$ and $C$. To protect the substrate from fluorides in the coating atmosphere, a thin $(\sim 0.01 \mu)$ coating was first applied to the bare $\mathrm{UO}_{2}$ by decomposing $\mathrm{W}(\mathrm{CO}) 6$ at $400 \mathrm{~F}$. The coating was then completed to produce 80 volume percent tungsten from $W_{6} 6$ as for Coating $B$.

Referring to the preparation of the initial layer from tungsten carbonyl, dense coating layers are obtained only under conditions that give high carbon contents, e.g., $>1000$ ppm. Because carbon contamination is also objectionable in this program, the thickness of this first layer was so severely limited that even if it is assumed that the layer is $W_{2} C$, the calculated contribution to the carbon content of the final material is $<5$ ppm.

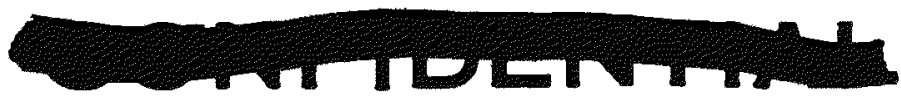




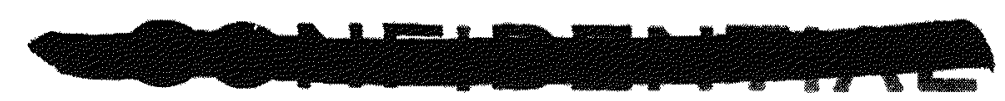

13

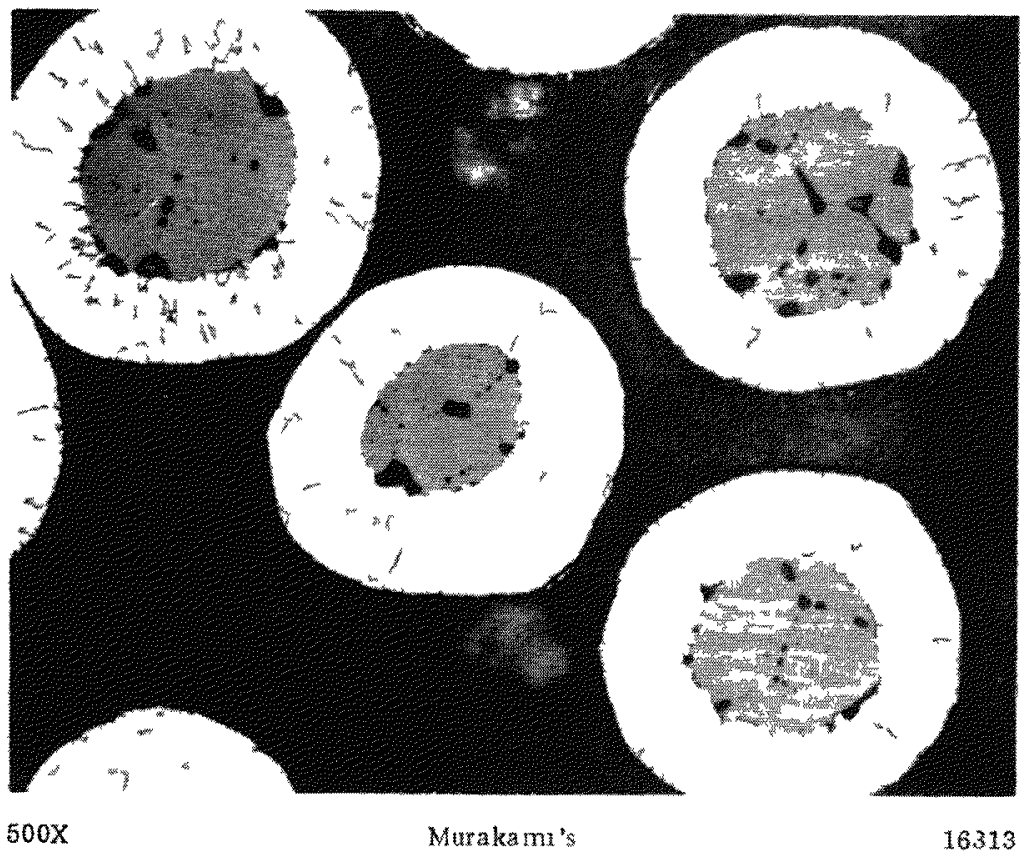

FIGURE 11. TUNGSTEN-COATED UO 2 PARTICLES PRODUC FD BY COATING AN INITIAL LAYER BY CARBONYL PROCFSSES AND THE RFMAINING COATING BY THE FLUORDE PROCESS (COATING C)

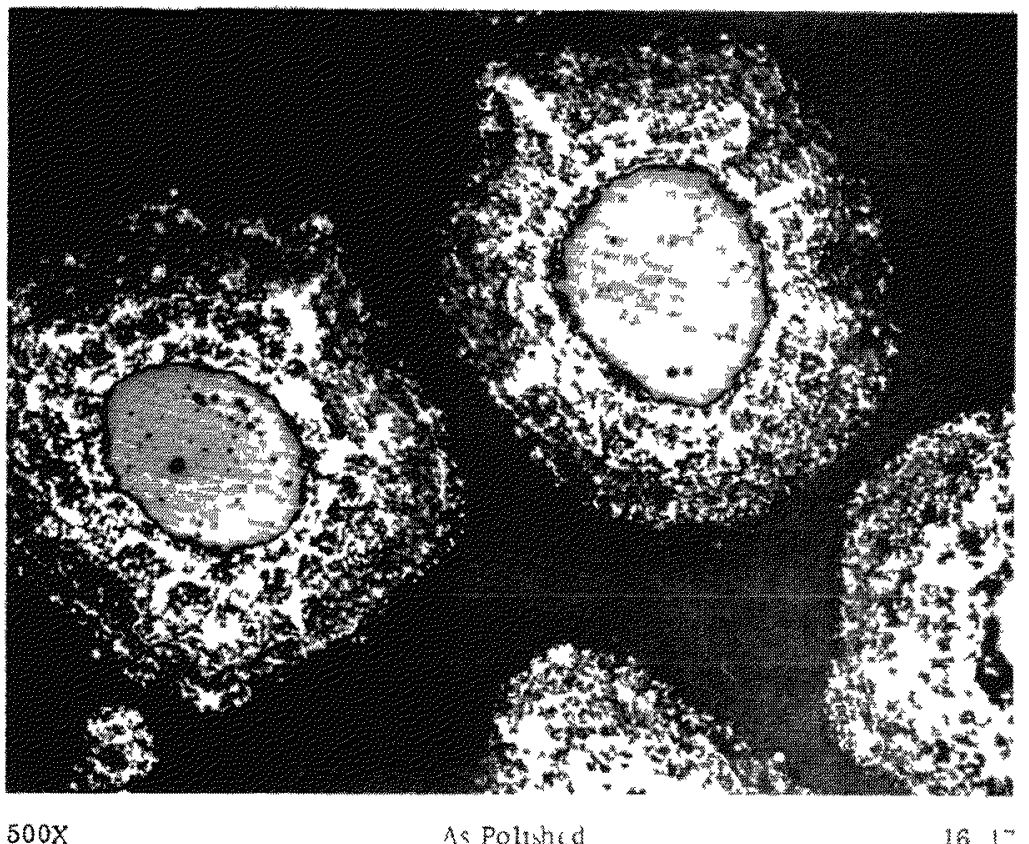

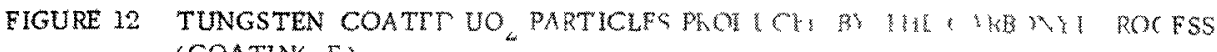
(COATING E) 


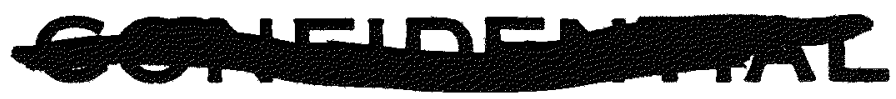

14

Comparison of carbon and fluorine analyses for Coatings $B, C$, and $D$ is required before this procedure can be evaluated. However, it is obvious that an optimum should exist for minimization of total contamination by fluorine and carbon.

Coating E. In the preparation of this material, contamination by halides was minimized by using a nonhalide coating process. The coating was prepared by decomposing $\mathrm{W}(\mathrm{CO})_{6}$ at $1850 \mathrm{~F}$ in an atmosphere of hydrogen containing 17 percent water vapor to avoid gross carbon contamination. Analysis of these particles has not been completed. Tungsten coatings prepared under these conditions are about 50 percent of theoretical density, as shown in Figure 12. The ready deformability of this type of coating may be advantageous in pressure bonding. Currently, the procedure for preparing this porous deformable type of tungsten coating is less well developed than those for the preparation of dense coatings from the halides, but pressure-bonding attempts will be made with this type of particle.

\section{Additional Studies of Materials}

During fuel-loss evaluations at NASA, a thoriated-tungsten matrix has decreased the weight los s recorded during 25 ten-minute thermal cycles to $4500 \mathrm{~F}$ by about one magnitude. This improvement suggests that future honeycomb samples should incorporate this material in the matrix. For this reason, a hydropressed pellet of coprecipitated 2 weight percent thoria-tungsten powder was sealed within a molybdenumlined tantalum container and pressure bonded at $2900 \mathrm{~F}$ and $10,000 \mathrm{psi}$ for 3 hours. The resulting microstructure, as shown in Figure 13, is of high density. A measured density was recorded as being 95.7 percent of theoretical, which is comparable to that of pure tungsten pressure bonded in a tantalum container under identical conditions, as shown in Figure 14. An encouraging aspect of this material is that the thoria remained uniformly dispersed and of 1-micron size. Consequently, the grain size of the thoriated tungsten is finer than that produced in pure tungsten (approximately 3 microns) by a factor of at least one-half. This fine grain size should contribute to longer life during service. Grain-size evaluations after heat treatments at $4500 \mathrm{~F}$ are being obtained.

\section{Phase II. Honeycomb Fabrication}

The basic approach to honeycomb fabrication involves the densification of coated particles within an array of soluble mandrels. Densification of the tungsten-coated fuel particles is achieved by gas-pressure bonding in sealed containers. For tungsten densification, molybdenum is the most appropriate refractory metal for container and mandrels, because it can be selectively removed by nitric acid solutions. Hence, all the honeycombs are being formed by packing tungsten-spheres (100- $\mu$ diameter) around a fixtured array of molybdenum mandrels in a molybdenum can. After densification, the container and fixtures are dissolved. With routine bonding parameters of temperatures exceeding 2900 degrees $F$ and a pressure over 10,000 psi, tungsten spheres reach densities of $95 \pm 4$ percent of theoretical. Similar densities are possible in fueled composites required in this project; however, initial fabrication studies in this phase have utilized tungsten spheres in lieu of the coated $\mathrm{UO}_{2}$ particles.

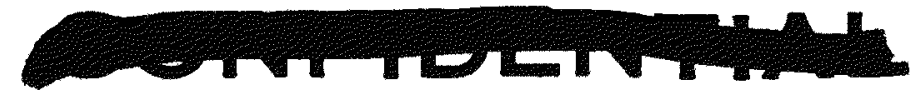




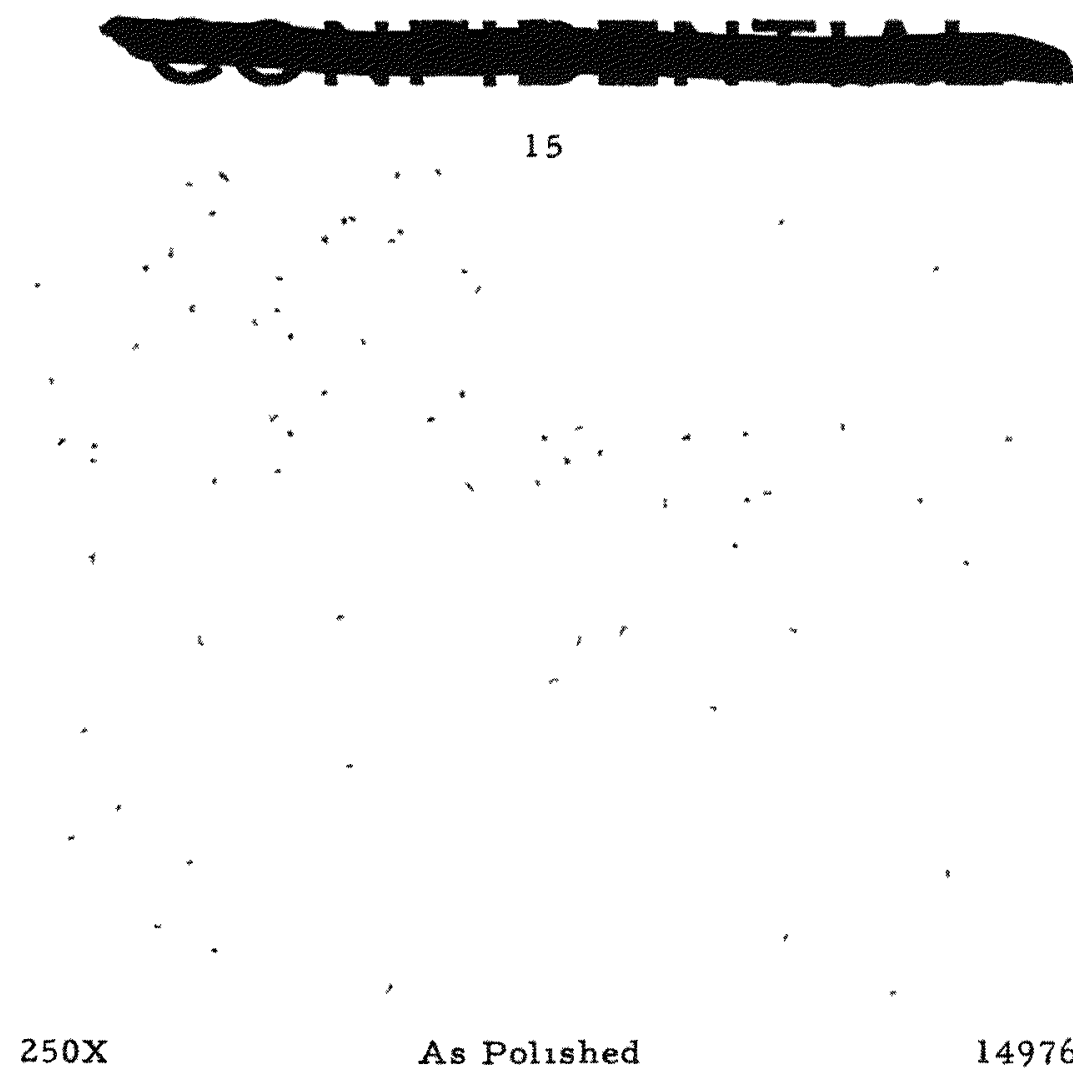

FIGURE 13. HYDROPRESSED TUNGSTEN-2 WEIGHT PER CENT THORIA POWDER AFTER HOT ISOSTATIC COMPACTION AT $2900 \mathrm{~F}$ AND 10,000 PSI FOR 3 HOURS

FIGURE 14 HYDROPRESSED PURE TUNGSTEN POWDER CONSOLIDATED UNDER THE SAME CONDITIONS AS ABOVE 


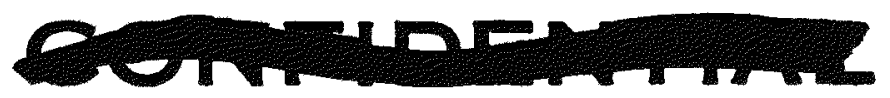

16

\section{Goals of Phase II}

The ultimate goal of this work includes the production of 20 honeycomb sections 2 inches in diameter by 1.5 inches long with 0.125 -inch hexagonal channels and $0.020-$ inch-thick separating webs. The webs are to be formed with tungsten-coated fuel particles plus any required dilution with pure tungsten particles to produce a uniform fuel loading of 20 volume percent $\mathrm{UO}_{2}$. This phase of the project is concerned with fixturing and loading techniques necessary to give the specified geometry. Since only the particles are densified, dimensional accuracy is limited by the fixtures or the container. The desired shapes can be achieved only if the shrinkage is uniform and predetermined. The desired eventual dimensional tolerance is 1 mil. Hence, precise shrinkage and fixturing tolerances must be determined from actual specimens.

The intermediate goals of the fabrication phase include

(1) Fixture accuracy,

(2) Uniform shrinkage, and

(3) High-density composites.

Each specimen represents modifications of existing techniques necessary to achieve tighter tolerances and maximum density in refractory composites.

Fabrication of Exploratory Specimens

With cross sections of $1 / 3$ powder and $2 / 3$ dense mandrels, the immediate question was how to obtain uniformity of compaction throughout the array. An initial honeycomb (Specimen H-1) 0.75 inch in diameter by 1.9 inches long was designed with 19 cyclindrical holes situated in a hexagonal array. The mandrels were 19 molybdenum rods, $1 / 8 \mathrm{inch}$ in diameter and 2 inches long. These rods were held in position by perforated molybdenum templates at the top and bottom of a molybdenum can (see Figure 15). Each template had been drilled to establish the spacing of $0.030 \mathrm{inch}$ between adjacent rods. Vibratory packing was used to fill the fixture with 100-micron tungsten spheres (Allied Chemical Company, Batch 41.3), and a green density of about 57 percent was attained. The as sembly was then doubly canned in molybdenum with an outer envelope of titanium before the bonding run. The purpose of the titanium can is to provide additional reliability in maintaining a vacuum-tight container during pressure bonding.

The sealed assembly was densified in a helium atmosphere at 10,000 psi for 3 hours at a maximum temperature of $2900 \mathrm{~F}$. After selective dissolution of the container and mandrels, the honeycomb (Figure 16) was sectioned and measured. An optical comparator showed an average web spacing of $0.0208 \mathrm{inch}$. Average hole size was 0.1238 inch. The holes lost about 1 percent of the original mandrel diameter, while the web spacing decreased nearly 31 percent. Actual measurement across six major diameters are shown for three internal sections and one diamete $r$ for each end in Table 3. Individual measurements reflect the variations due to the wall roughness of one particle diameter. Since future honeycombs will include finer particles, only the averaged diameters (per section) may be compared. From end to end, this variation

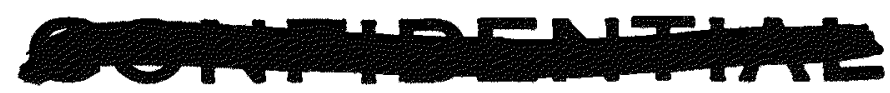




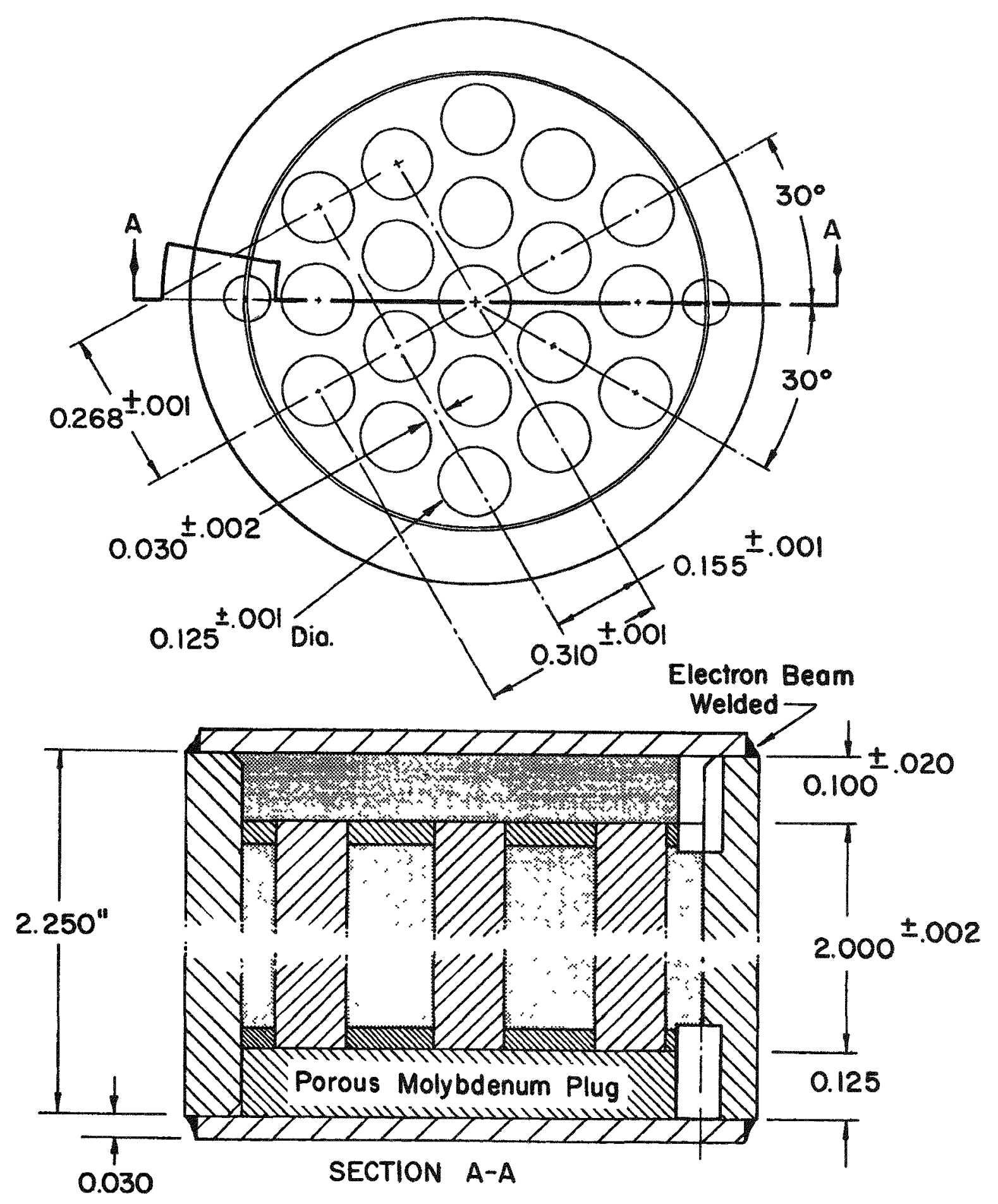

FIGURE 15. MOLYBDENUM HONEYCOMB FIXTURE WITH TUNGSTEN GRANULES FOR SPECIMEN H- 1 


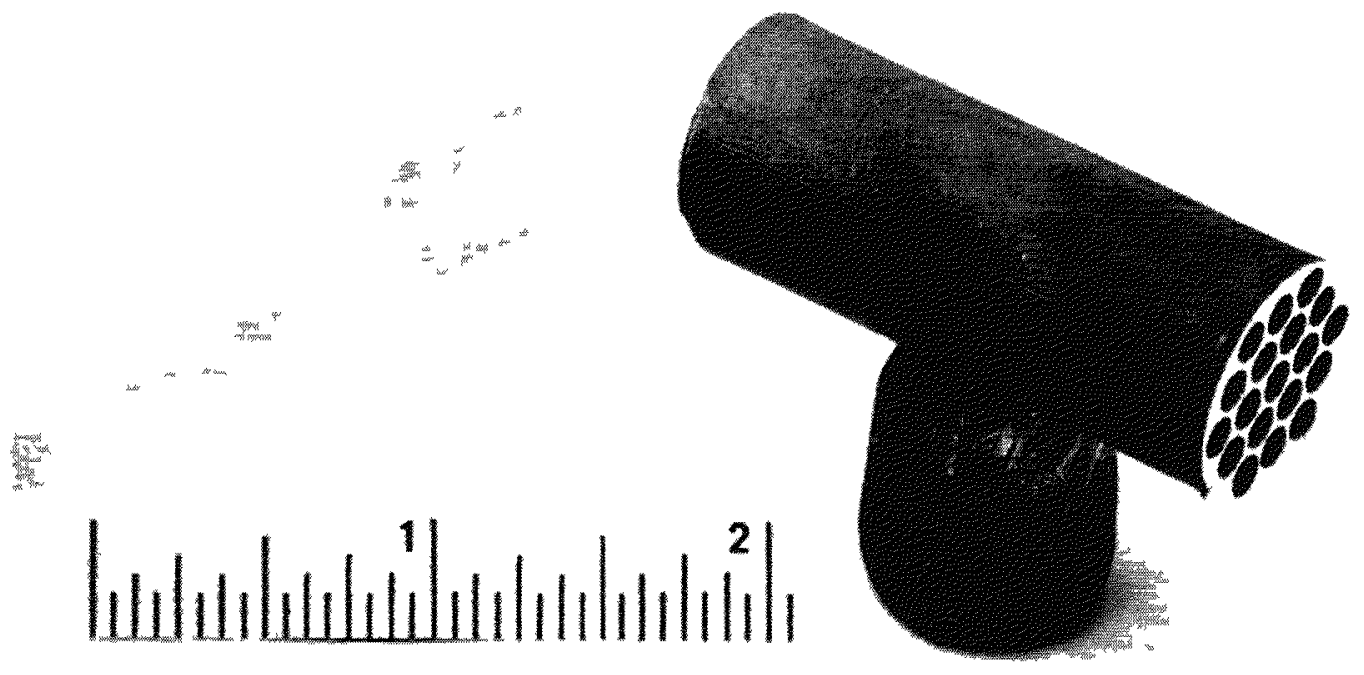

15982

FIGURE 16. TUNGSTEN HONEYCOMB (H-1) FABRICATED BY GAS-PRESSURE BONDING

Average web thickness: 0.0208 inch, 
TABLE 3. HOLE DLAMETER AND WEB THICKNESS IN SPECIMEN H- 1

\begin{tabular}{|c|c|c|c|c|c|c|c|c|c|c|c|c|c|}
\hline \multirow{2}{*}{$\frac{\text { Section }}{\text { A (end) }}$} & \multirow{2}{*}{$\begin{array}{c}\begin{array}{c}\text { Diameter, } \\
\text { mils }\end{array} \\
\text { I } 750.3\end{array}$} & \multicolumn{5}{|c|}{ Holes, mils } & \multicolumn{6}{|c|}{ Webs, mils } & \multirow{2}{*}{$\frac{\begin{array}{c}\text { Section } \\
\text { mils }\end{array}}{21.1}$} \\
\hline & & 123.9 & 124.8 & 123.2 & 124.0 & 124.3 & 21.9 & $20.4^{(a)}$ & $21.0^{(a)}$ & $20.6^{(a)}$ & $22.2^{(a)}$ & 24.0 & \\
\hline $\mathrm{B}$ & I 746.8 & 119.7 & 125.3 & 124.9 & 124.9 & 123.8 & 16.5 & 21.2 & 25.4 & 20.3 & 21.5 & 23.2 & 22.15 \\
\hline B & II 750.6 & 123.9 & 124.1 & 124.0 & 123.1 & 123.7 & 21.9 & 24.5 & 19.6 & 22.9 & 22.5 & 20.4 & \\
\hline B & III 746.0 & 123.5 & 125.0 & 124.1 & 125.3 & 123.7 & 21.3 & 19.4 & 21.0 & 21.7 & 25.8 & 14.8 & \\
\hline C & I 743.8 & 123.7 & 123.3 & 123.1 & 122.1 & 123.1 & 21.8 & 21.0 & 20.6 & 22.9 & 23.1 & 19.1 & 20.74 \\
\hline C & II 743.5 & 121.8 & 124.0 & 122.9 & 124.1 & 123.5 & 21.5 & 22.5 & 20.0 & 19.3 & 19.4 & 24.5 & \\
\hline C & III 736.8 & 123.3 & 123.3 & 123.9 & 119.1 & 123.5 & 21.8 & 21.0 & 20.0 & 19.1 & 20.0 & 21.8 & \\
\hline$D$ & I 743.5 & 124.6 & 123.1 & 124.3 & 124.5 & 124.2 & 21.1 & 22.3 & 20.6 & 20.0 & 18.0 & 20.8 & 19.86 \\
\hline $\mathrm{D}$ & II 746.1 & 124.8 & 124.5 & 123.9 & 124.6 & 123.4 & 23.2 & 18.3 & 20.2 & 19.9 & 20.1 & 23.2 & \\
\hline$D$ & III 742.2 & 123.7 & 124.1 & 124.2 & 124.2 & 122.6 & 23.7 & 19.9 & 19.0 & 19.2 & 20.8 & 20.8 & \\
\hline$E$ (end) & III 749.3 & 124.2 & 127.2 & 125.1 & 124.2 & 122.3 & 22.2 & 24.0 & 20.9 & 20.0 & 20.2 & 19.0 & 20.4 \\
\hline
\end{tabular}




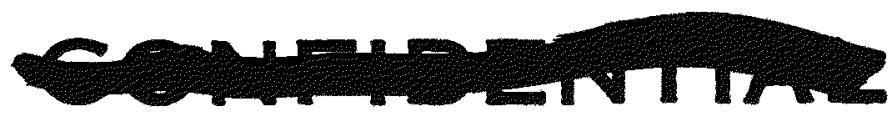

20

was slightly over 1 mil. Thus, the specified tolerance for web thickness appears practicable.

The uniformity of the outer diameters and internal shrinkage indicates that deformation occurred primarily in the radial direction. The length of the specimen decreased less than 5 percent. Fortunately, the thin end fixtures did not interfere with uniform construction of the entire assembly. In general, the original jig tolerance of 2 mils was maintained in hole location and alignment.

The shrinkage data were applied to the design of a model with 61 hexagonal holes. This version doubled the number of holes arranged radially from the central mandrel. The primary modifications were in the number and shape of the mandrels. The availability of molybdenum hex rod simplified the fixture preparation. Drawn hex stock, 0.125 inch across flats, was purchased from the Refractomet Division of Universal Cyclops Steel Company. After additional pickling and annealing, this stock had a width of 0.124 inch. The size reduction permitted a tight fit in drilled molybdenum end plates.

The design and assembly of the first 61-hole honeycomb (Specimen H-2) has been completed. Various design changes were made to further approach the ultimate geometry. Modifications included were

(1) Fixturing of hexagonal stock in round holes,

(2) Decreased web thickness,

(3) Increased proportion of mandrel area,

(4) Thin-walled container,

(5) Increased green density with identical granules, and

(6) Elevated bonding pressure.

Individual alignment of the cores was achieved by slotting each end for a temporary rib. The drilled-hole template permitted a minimum spacing of 0.027 inch which was reduced 10 percent below that of the previous spacing. Prolonged vibratory-loading technique also boosted the green density to 65 percent. Increased green density and the reduced proportion of spheres should contribute to less shrinkage, thus requiring a decrease in the initial webbing thickness. Conversely, higher bonding pressure should increase shrinkage but also the final density. This specimen will be densified and evaluated before another identical fixture is loaded.

\section{End-Fixture Evaluation}

Since the current fixture method forms a rough end, the circular-hole template may be undesirable for fueled honeycombs. A variety of tighter-fitting end fixtures have been considered. Three of the most promising include

(1) Volatile adhesives on molybdenum end plates,

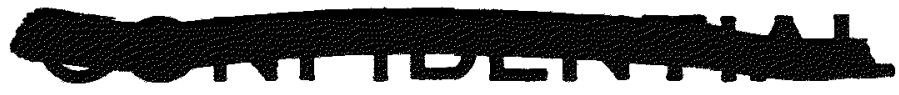


21 and 22

(2) Die-formed, porous, molybdenum plugs, and

(3) Photoetched molybdenum disks.

The last method is being investigated first, since it offers the greatest flexibility in spacing. In the event these methods are ineffective, the ends may be loaded with pure tungsten and later removed by grinding.

\section{FUTURE WORK}

Planned work for Phase I includes a continuation of tests whereby hot vacuum outgassing can be more effectively evaluated and the cause of the oxide phase can be determined so as to eliminate it. Also, the coated particles will be evaluated with regard to densification characteristics, purity, and behavior during qualification tests. The use of thoriated-tungsten powder densified by pressure bonding will be submitted to experiments to determine its behavior in simulated test conditions. These data should be available by the next report period.

Future work for Phase II includes an evaluation of fixturing techniques, which will be confined to shrinkage determinations on porous molybdenum parts and to photoetching of hexagonal holes. The current fixture method, with hexagonal slotted mandrels, will be used to produce the next samples.

In the next quarter, fueled composites will be fabricated. Initially, two 61-hole models will be assembled. One will contain a blend of coated spheres with finer tungsten particles, and the other will contain only coated particles. If satisfactory densities are achieved, fabrication of a full-scale prototype will be attempted. If densities are low, process refinements will be evaluated in the smaller versions.

GRG:PWC:PJG:WJW/mld 
DISTRIBUTION LIST

NASA Lewis Research Center ( $3+2$ repro) NASA Scientific and Technical Information 21000 Brookpark Road

Cleveland, Ohio 44135

Facility $(6+2$ repro)

Attention: Paul Sikora

NASA Lewis Research Center (1)

21000 Brookpark Road

Cleveland, Ohio 44135

Attention: Technical Utilization Office, MS 3-16

NASA Lewis Research Center (2)

21000 Brookpark Road

Cleveland, Ohio 44135

Attention: Library

U. S. Atomic Energy Commisston (3)

Technical Reports Library

Washington, D. C.

A. E. C. Headquarters (1)

Div, of Reactor Development

Washington, D. C.

Attention: S. Christopher

National Aeronautics and Space

Administration (2)

Washington, D. C. 20546

Attention: NPO

NASA Lewis Reseaxch Center (1)

21000 Brookpark Road

Cleveland, Ohio 44135

Attention: Office of Reliability and Quality Assurance

NASA Ames Research Centex (1)

Moffett Field, California 94035

Attention: Library

NASA Goddard Space Flight Center (1)

Greenbelt, Md. 20771

Attention: Library

NASA Lewis Research Center (1)

21000 Brookpark Road

Cleveland, Ohio 44135

Box 5700

Bethesda, Md.

Attention: NASA Representative

NASA Lewis Research Center (1)

21000 Brookpark Road

Cleveland, Ohio 44135

Attention: Reports Control Office

U. S. Atomic Energy Commission (3)

Technical Information Service Extension

P. O. Box 62

Oak Ridge, Tenn.

National Aeroanutics and Space

Administration (1)

Washington, D. C. 20546

Attention: G. Deutsch

NASA Lewis Research Center

21000 Brookpark Road

Cleveland, Ohio 44135

Attention: (One copy to each)

Nuclear Rocket Technology Office, MS 54-1

Neal Saunders, MS 105-1

S. Kaufman, MS 49-2

T. Moss, MS 500-309

J. Creagh, MS 500-309

H. Smreker, MS 54-1

NASA Flight Research Center (1)

P. O. Box 273

Edwards, California 93523

Attention: Library

Jet Propulsion Laboratory (1)

4800 Oak Grove Dr.

Pasadena, California 91103

Attention: Library

NASA Langley Research Center (1)

Langley Station

Hampton, Va. 23365

Attention: Library

Attention: John J. Fackler

Contracting Officer, MS 54-1 


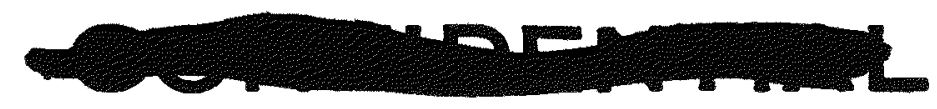

DISTRIBUTION LIST

(Continued)

NASA Marshall Space Flight Center (1) Huntsville, Ala. 35812

Attention: Library

Argonne National Laboratory (2)

9700 South Cass Avenue

Argonne, Illinois

Attention: J. Schumar

R. Noland

Oak Ridge Gaseous Diffusion Plant (1)

Oak Ridge, Tenn.

Attention: $P$. Huber

Battelle Memorial Institute (1)

505 King Avenue

Columbus, Ohio

Attention: E. Hodge

Sylvania Electric Products (1)

Chemical \& Metallurgical Division

Towanda, Pennsylvania

Attention: M. Macinnis

United Nuclear Corp. (1)

New Haven, Conn.

Attention: E. Gordon

General Atomic Division (1)

General Dynamics Corp.

P. O, Box 608

San Diego, California 92112

Attention: A. Weinberg

Minnesota Mining \& Manufacturing

Co. (I)

Nuclear Products Department

St. Paul, Minnesota

Attention: J. Ryan

General Electric Co.

Vallecitos Atomic Laboratory

P. O. Box 846

Pleasanton, California

Attention: Dr. A. Kaznoff
NASA Manned Spacecraft Center (1)

Houston, Texas 77001

Attention: Library

NASA Western Operations (1)

150 Pico Blvd.

Santa Monica, California 90406

Attention: Library

Hanford Laboratories (1)

Richland, Washington

Attention: $F$. Albaugh

General Electric - NMPO (1)

P. O. Box 15132

Evendale, Ohio 45215

Attention: J. McGurty

Nuclear Materials \& Equipment Corp. Apollo, Pennsylvania

Attention: B. Vondra

Westinghouse Electric Corp. (1)

Astronucleax Laboratory

Box 10864

Pittsburgh, Pennsylvania 15236

Attention: D. Thomas

Union Carbide Corp. (1)

Nuclear Products Dept.

Lawrenceburg, Tenn. .

Attention: W. Eatherly

Atomics International Division (1)

North American Aviation

8900 Desota Avenue

Canoga Park, California

Attention: S. Carneglia

Martin - Marietta Corp.

Nuclear Division

Baltimore, Md. 21203

Attention: C. Eicheldinger 